IMTC 2005 - Instrumentation and Measurement

Technology Conference

Ottawa, Canada, 17-19 May 2005

\title{
Finite Element Modeling and Simulation of Probe System
}

\author{
Mohd Rizal Salleh, Qing Ping Yang, Barry Jones \\ School of Engineering and Design, Brunel University, Middlesex UB8 3PH, UK \\ Tel: 441895 27400, Fax: 441895 269763, Email: emstppy@brunel.ac.uk
}

\begin{abstract}
Coordinate Measuring Machines (CMMs) have been widely used for enhancing product quality, productivity and reliability. This powerful instrument assists the user by providing them with highly accurate and reliable measurement results. Many studies involving the application of various different methods have been carried out to enhance the performance of CMM. This paper discusses the application of Finite Element Analysis (FEA) to study the probe system of CMM. Finite element modeling is utilized to investigate the displacement of the probe stylus, pretravel variation (lobing effects) and the associated measurement uncertainty. Different characteristics of styli have been considered and the corresponding effects on the probe operation are reported.
\end{abstract}

Keywords - Coordinate Measuring Machine (CMM), Probe, Finite Elements Analysis (FEA), Modeling, Simulation

\section{INTRODUCTION}

The demand for high precision measuring instruments in non-laboratory environment increases day by day. Manufacturers need such instruments to enhance product quality, productivity and reliability. These measuring instruments provide them with precise and highly accurate data, and enable them to shorten cycle time and reduce measurement errors and inspection time. This ensures that their products can remain competitive in the global market. Coordinate Measuring Machine (CMM) is one of the most reliable metrological instruments.

The performance of a CMM depends upon various factors, both internal and external. It has been recognized that CMM hardware, part form error, sampling strategy, algorithm selection, algorithm implementation and fitting algorithm can all influence CMM measurements [1]. Error mapping software is now widely available to compensate for geometric error, which contribute more than $40 \%$ to the total machine errors [2]. The probe system of CMM including probe and stylus has become the most critical part of the machine. Indeed, a probe sometimes has been described as the heart of a CMM. This is true not only because of its function in the $\mathrm{CMM}$, but also it produces larger errors than other parts of the machine [3].

CMM users need good skills in selecting and configuring the probe, probe head, styli, interface and accessories for a given application, and only well-trained users can establish efficient probe system for measuring tasks. Current practices have largely relied on choosing probes of better performance, selecting stylus configuration of shorter length and higher stiffness, using smaller probing forces, and careful sampling strategy [4]. Even so, large probe errors can still be present in practical measurements due to the complicated operation of probes.

A powerful technique for error compensation was reported in [4], involving the use of artificial neural networks with very significant error reductions demonstrated. It however has practical limitation in that the neural network model is based upon experimental data and hence requires a large amount of data. This can be very difficult since the probe conditions change frequently.

It is thus clear that a better approach is needed, which should be able to model the complicated operations of a probe system and at the same time does not require a large amount of experimental data. This paper discusses the use of finite element modeling (FEM) against the above background.

\section{PROBE MODELING}

Various types of probes have become available with a range of functions and features. However, many users continue to use the conventional ones because of their low cost, adequate level of accuracy and performance. This study has first considered a Renishaw TP2-5W probe because the uncertainty level associated with this type of probe is higher than other contact probes, as reported in [5], and it is the type of probe most commonly used by CMM users.

In this study, the structural model of probe and stylus has been significantly simplified, although, in general, it is still carrying the important features of a TP2 probe system. Figure 1 shows the simplified TP2 probe system model. This model depicts the probe structure which consists of a vertical stem carrying a ruby tip. The stem is completely held by three arms which are positioned horizontally $120^{\circ}$ apart. These arms rests on three rectangular blocks, each serves as a supporting platform. A hollow cylinder block has been used to model a spring that rests at the top center of the stem and its function is to restore stem to its original position after deflection. The characteristic of each part of the probe model is given in Table 1: 
Table 1: Mechanical properties of the probe system

\begin{tabular}{|c|c|c|c|}
\hline Material & $\begin{array}{c}\text { Young modulus } \\
\left(\mathbf{N} / \mathbf{c m}^{\mathbf{2}}\right)\end{array}$ & $\begin{array}{c}\text { Density } \\
\left(\mathbf{g} / \mathbf{c m}^{\mathbf{3}}\right)\end{array}$ & $\begin{array}{c}\text { Poisson's } \\
\text { ratio }\end{array}$ \\
\hline Steel & $1.90 \times 10^{7}$ & 7.75 & $0.27 \sim 0.30$ \\
\hline Tungsten & $6.75 \times 10^{7}$ & 19.29 & 0.24 \\
\hline Ruby & $3.51 \times 10^{5}$ & 3.96 & 0.33 \\
\hline Rubber & $7.00 \times 10^{-8}$ & 1.05 & $0.45 \sim 0.5$ \\
\hline
\end{tabular}

The model is fully restrained at the top of the spring and its three rectangle support blocks. The appropriate force is applied on the ruby ball and the corresponding displacements are analyzed.

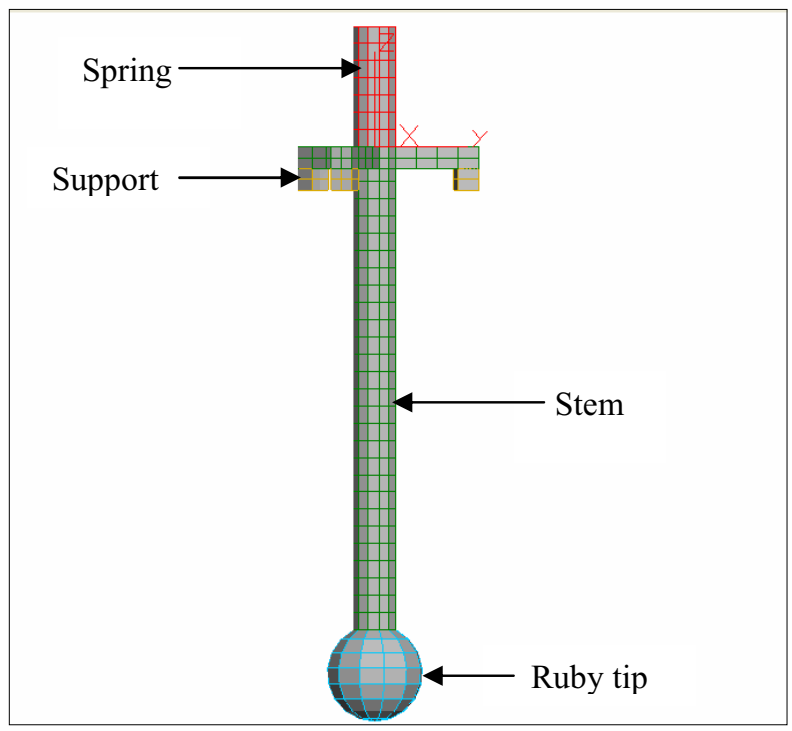

Figure 1: The simplified model of TP2-5W Probe System

In the preliminary investigation, two parameters are considered, i.e. the length and diameter of probe's stylus. Two different stylus lengths, $10 \mathrm{~mm}$ and $20 \mathrm{~mm}$ with a stylus diameter of $2.5 \mathrm{~mm}$ and ball tip of $5 \mathrm{~mm}$, are modeled and the stylus displacements with different probing positions and directions are compared and analyzed.

Three sets of models were investigated. The first set involves the probing force applied at the equator of the ruby ball every $30^{\circ}$, the second set with the probing force applied at the bottom part of ruby tip at a latitude of $45^{\circ}$ and for the third set, the probing force is applied at several latitudes at the bottom part of the tip, normal to the stylus ball surface.

The FEA is only performed on one half of the ruby ball because of the symmetrical construction. The displacement produced by the other half of the ball will be the same.

Theoretically, the stylus displacement relies on various factors, such as probing direction, probing force, materials, stylus length and diameter, which means that by carefully choosing these factors probe lobing may be minimized and measurement uncertainty can thus be greatly reduced. Figure 2 shows the force applied to the simplified TP2 probe model at an angular step of $30^{\circ}$. The bold arrows showed two extreme probing directions where displacement variations will occur. The maximum probing force is recorded when the stylus approaches from direction "a" to lift arms "II" and "III" up, whilst minimum force may be required when stylus approaches from direction "b". Consequently, the displacement recorded for the first approach direction should be higher relative to other positions on ruby ball.

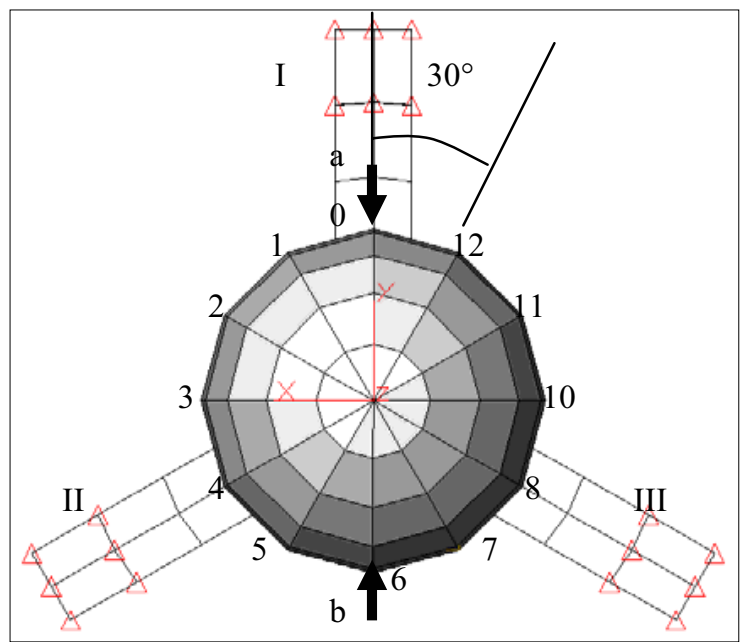

Figure 2: Bottom view of probe model with its probing directions at an angular step of $30^{\circ}$

\section{MODELING RESULTS}

This section will detail the results of the above three sets of probe models, with different probing positions and directions.

\section{A. Horizontal probing direction at the stylus ball equator}

The probe system has been modeled with two different stylus lengths, $l_{1}=20 \mathrm{~mm}$ and $l_{2}=10 \mathrm{~mm}$, and both are applied with a force of $0.15 \mathrm{~N}$ at the equator of the ruby ball. For this purpose, one FEA model is required to simulate each probing direction, and the stylus displacement results of these models (seven models for seven probing directions) have been summarized in Table 1 and 2.

Table 1: Displacement of $20 \mathrm{~mm}$ probe

\begin{tabular}{|c|c|c|c|c|c|c|c|}
\hline$\Theta\left({ }^{\circ}\right)$ & 0 & 30 & 60 & 90 & 120 & 150 & 180 \\
\hline$\delta(\mu \mathrm{m})$ & 2.337 & 3.319 & 3.446 & 2.419 & 3.193 & 3.304 & 2.522 \\
\hline
\end{tabular}


Table 2: Displacement of $10 \mathrm{~mm}$ probe

\begin{tabular}{|c|c|c|c|c|c|c|c|}
\hline$\Theta\left({ }^{\circ}\right)$ & 0 & 30 & 60 & 90 & 120 & 150 & 180 \\
\hline$\delta(\mu \mathrm{m})$ & 1.585 & 2.226 & 2.166 & 1.632 & 2.303 & 2.231 & 1.686 \\
\hline
\end{tabular}

The figures recorded in the tables have shown that there is a good agreement with the theory, which generally means that the component characteristics play an important role in the stylus displacement and that longer stylus generally results in larger displacement.

The simulation has also clearly shown the probe lobing (Figure 3). Additionally, the displacement for stylus length $l_{1}$ is slightly larger than that for $l_{2}$.

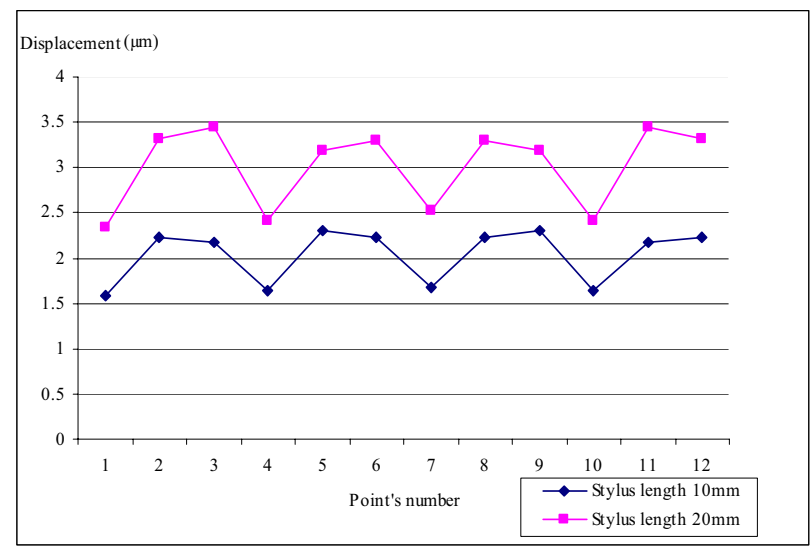

Figure 3: Simulated stylus displacement with horizontal probing directions at the equator of stylus ball

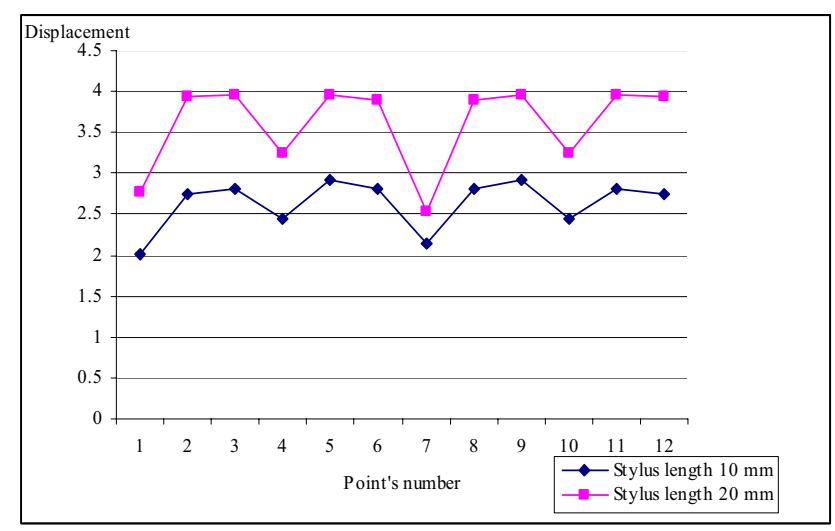

Figure 4: Simulated stylus displacement with horizontal probing directions at the latitude of $45^{\circ}$

\section{B. Horizontal probing direction at the latitude of $45^{\circ}$}

Similar investigation was repeated at the latitude of $45^{\circ}$ position (bottom part) of ruby ball, as shown in Figure 4. By comparing the two graphs at the equator and the latitude of $45^{\circ}$, it can be seen that the latter produces greater displacements than the former for both stylus lengths.
Therefore, the results agree with the general recommendation that the most appropriate direction for minimizing probe lobing is normal direction, i.e. probing perpendicularly to the surface.

\section{Normal probing direction at different latitudes.}

The stylus displacement was further studied with the probing point at four different latitudes, a, b, c and d, $30^{\circ}$ apart in the vertical plane, as shown in Figure 5. A normal probing direction was used and the applied probing force was $1.5 \mathrm{~N}$. The stylus length was $10 \mathrm{~mm}$ with stylus diameter and ball diameter remained unchanged.

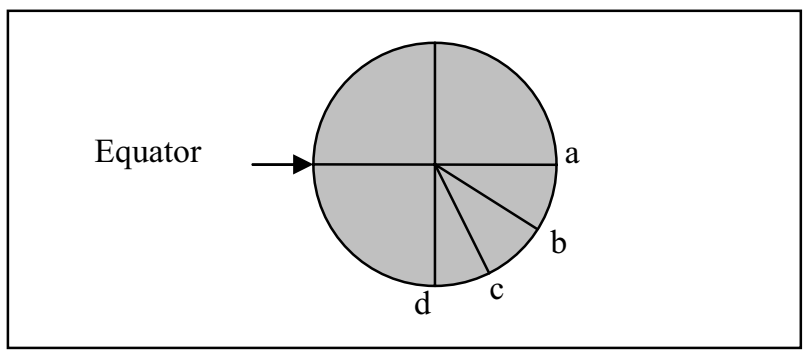

Figure 5: Index points of approach direction straight down of ball

The displacement results from the FEA modeling are given in the following table. Among the four index positions, point $d$ corresponds to the smallest displacement, contacts at points $b$ and $c$ resulted in relatively larger displacements. Point a is somewhere in between.

Table 3: Stylus displacement with the contact point at different latitudes (stylus length $10 \mathrm{~mm}$ )

\begin{tabular}{|c|c|c|c|c|}
\hline Index & $\mathrm{a}$ & $\mathrm{b}$ & $\mathrm{c}$ & $\mathrm{d}$ \\
\hline$\delta(\mu \mathrm{m})$ & 1.682 & 2.112 & 2.265 & 0.507 \\
\hline
\end{tabular}

\section{CONCLUSIONS}

This paper has presented a simplified FEA model of the probe system. The preliminary results have demonstrated lobing effects, significance of probing directions and other characteristics associated with probe operation, i.e. different stylus lengths, probing positions. Although the preliminary results are only concerned with the basic operation of probe system, the model can be further refined and, more importantly, can be used repeatedly with different operation conditions, e.g. different stylus lengths, probing positions and directions, probing forces, probe angles, stylus rigidities, sizes, weights, etc. The operation and characteristics of probe system can therefore be comprehensively studied. Additional and comprehensive results involving different probe characteristics will be reported in the future. 


\section{REFERENCES}

[1] J. A. Bosch, "Coordinate Measuring Machines and Systems", Marcel Dekker, Inc., 1995.

[2] S. D. Murphy, "In-process Measurement and Control", Marcel Dekker Inc., 1990.

[3] Q. Yang and C. Butler, "A 3-D Non-Contact Trigger Probe for Coordinate Measuring Machines", Journal of the International Measurement Confederation, Vol. 17, No. 1, pp 39-44, 1996.

[4] Q. Yang et. al., "Error Compensation of Touch Trigger Probe", Journal of the International Measurement Confederation, Vol. 18, No.1, pp 47$57,1996$.

[5] Renishaw, "Touch Trigger Probe Performance Comparison", http://www.renishaw.com, 2005.

[6] A. Balsamo et. al., "Evaluation of CMM Uncertainty through Monte Carlo Simulation", Annals of CIRP, Vol. 48/1, pp 425-428, 1999.

[7] A. Wozniak and M Dobosz, "Metrological Feasibilities of CMM Touch Trigger Probes. Part I: 3D Theoretical Model of Probe Pre-travel", Measurement 34, pp 273-286, 2003. 